\title{
Arbor
}

\section{Programas de Investigación en Paleobiología y Teoría evolutiva}

\author{
Antonio Rosas González
}

Arbor CLXXII, 677 (Mayo), 41-57 pp.

Se presenta una discusión del papel actual de la paleontología en el estudio de la evolución orgánica. Diferentes descubrimientos, tanto teóricos como empíricos, están cuestionando algunos de los principios básicos del paradigma neo-darvinista. La irrupción de la genética del desarrollo y la noción de procesos que limitan el potencial de variación del fenotipo han abierto nuevos programas de investigación. Desde la paleontología se desarrollan los fundamentos de una teoría macroevolutiva. El estudio de la morfología, un tema clásico de las ciencias naturales, vive un resurgir a la luz de los nuevos datos y enfoques. Quedan, no obstante, importantes incógnitas por resolver ante la pregunta de cómo y porqué cambian los organismos. La integración de los nuevos datos de la neontología en un contexto temporal amplio (tiempo geológico) proporciona a la paleontología una función importante en el momento actual de la investigación en biología evolutiva.

\section{Introducción}

La comprensión de la complejidad de un planeta Tierra en constante cambio solo es posible mediante la investigación de los procesos naturales que operan a diferentes escalas espacio-temporales. Solo la Paleontología accede a escalas de interacción de los procesos bióticos y físicos que excedan tiempos superiores a unos pocos cientos de años. Una dimensión temporal amplia en la investigación de las dinámicas de la vida no es solo un complemento al conocimiento; en muchas ocasiones es sencillamente imprescindible. 
Las pruebas de la realidad física de la evolución proceden de cuatro disciplinas clásicas de la biología: la Anatomía Comparada, la Embriología, la Biogeografía y la Paleontología. De estas disciplinas, la Paleontología proporciona la evidencia más tangible del cambio de los organismos a lo largo del tiempo. Sin embargo, una vez superada la constatación de lo evidente del fenómeno de la evolución, la ciencia trata de profundizar en el conocimiento de las causas y mecanismos que operan en la naturaleza. Y los paleontólogos nos preguntamos ¿qué papel juega la Paleontología en el conocimiento de los procesos y las causas de la evolución?

La Comunidad Europea y el gobierno de los Estados Unidos han solicitado en los últimos años informes detallados sobre la pertinencia de la investigación en diferentes áreas, entre ellas la Paleontología (Fergurson, 1997; Futuyma et al., 1997). Lejos de verse socavada en sus apoyos formales, la Paleontología emerge como una disciplina de futuro (Jablonski, 1999).

\section{El sentido de la Paleontología}

La paleontología es la ciencia de los fósiles. Es decir, la disciplina científica que usando como objeto material de estudio los restos y/o señales de organismos del pasado, aborda todas aquellas cuestiones relacionadas con la historia de la vida en la Tierra y sus aplicaciones a otros saberes. Formalmente, la paleontología ha sido subdividida en tres disciplinas básicas: la biocronología, la tafonomía y la paleobiología (ver Fernández López, 1989; López-Martínez y Truyols, 1994). En este trabajo nos centraremos en la paleobiología, cuyo objetivo más general versa sobre la reconstrucción y estudio de la historia de la vida. Esta puede ser entendida como una sucesión de acontecimientos en la historia de los distintos linajes de la vida. Y puede, además, ser entendida como un entramado de procesos bióticos y abióticos a la espera de descubrir sus relaciones, sus causas y las variables que los rigen. Ambas aproximaciones son necesarias y complementarias, aunque quizá una aproximación procesual presenta en la actualidad un mayor atractivo. En la práctica, las diferentes aproximaciones a la paleobiología puede ser resumidas en un triple proceso: identificar los eventos bióticos del pasado, conocer los procesos que los han modelado y reconstruir los medios ecológicos donde se han producidos estos.

En el contexto del paradigma del neo-darvinismo, la paleontología ha sido objeto de fuertes críticas epistemológicas que han desembocado en cuestionarse el valor de los estudios paleontológicos. Dos son los argu- 
mentos sobre los que han recaído estas críticas. Por un lado, la imperfección del registro fósil, aludiéndose que la falta de registro puede proporcionar una imagen sesgada del tempo y la secuencia real de los acontecimientos evolutivos. Por otro, se ha argumentado que los procesos evolutivos no fosilizan; es decir, que los procesos solo se pueden abordar en lo vivo. En este paradigma todo lo que la paleobiología puede hacer respecto a los estudios evolutivos es que sus datos no contradigan lo que genéticos y evolucionistas sugieren (Huxley, 1942). En este caso la paleobiología solo puede aspirar a proporcionar fósiles interesantes y documentación.

Una defensa a estas críticas a la paleontología evolutiva se puede argumentar en torno a planteamientos generales. La ciencia actual tiende a un planteamiento reduccionista al buscar las causas de los fenómenos naturales, en este caso biológicos, en sus bases moleculares y bioquímicas. Por el contrario, la paleontología trata con procesos que se extienden en escalas temporales muy superiores a las que aborda la neontología, circunstancia por la que sus estudios tienden hacia una perspectiva más holística. Sin embargo, al margen de discusiones generales, en un ambiente altamente competitivo por la consecución de fondos para la investigación, el interés de una disciplina debe estar especialmente bien definido. En este sentido recientemente se han elaborado una serie de informes por comités de expertos para responder a la pregunta: ¿que puede aportar la paleontología a la ciencia del siglo XXI?

Fergurson (1997), en un informe para la Unión Europea, responde con una serie de argumentos resumidos en los siguientes puntos.

1. La paleontología representa uno de los pilares sobre los que se sigue construyendo la teoría evolutiva. Costaría mucho trabajo mantener la teoría evolutiva sin la información que proporciona el registro fósil. Desde un punto de vista teórico, el modelo del equilibrio puntuado da una nueva visión del proceso evolutivo de lo que cabe esperar en el registro fósil; no cabe esperar toda la serie gradual de cambios de forma que propone el esquema gradualista. Además, los datos del registro fósil son un modo de testar hipótesis filogenéticas, hoy más necesarias que nunca; por ejemplo, las filogenias moleculares.

2. El registro fósil es único e imprescindible al ser la única fuente de datos del registro histórico de la vida que contempla tiempos de ordenes de magnitud inaccesibles a otras disciplinas. En este sentido, la paleontología proporciona una información vital sobre cambios en climas y ecosistemas del pasado. En otro orden de cosas, el estado de preservación de los fósiles -tafonomía- proporciona información sobre diagénesis y tectónica. Además, los fósiles se usan para datar secuencias geológicas. 
3. Interés genuino y legítimo de nuestra especie por conocer nuestros ancestros. Todos los informes consultados coinciden en señalar que la paleontología humana es una disciplina con la suficiente entidad para justificar el ser uno de los pilares de la paleontología. La paleontología humana es, además, un una ciencia básica, y en cierto modo aplicada, puesto que tiene un rendimiento inmediato en la cultura, con implicaciones en ética y derecho. La paleontología humana arrastra y da trabajo a otros paleontólogos. Hoy en día no se entiende el estudio de la evolución humana sin el concurso de otras especialidades paleontológicas y ciencias afines tales como las de mamíferos, pólenes, zooarqueología, etc.

$\mathrm{El}$ aspecto que más nos ocupa en esta ocasión concierne al desarrollo de la teoría evolutiva. La vida es un fenómeno histórico y como tal solo es posible comprender mejor su naturaleza bajo la integración de los datos disponibles en un contexto temporal. Por eso se dice que la evolución es la única teoría capaz de abarcar y dar sentido a las múltiples disciplinas de la Biología. En un momento de intenso debate intelectual, en un documento elaborado por 8 importantes sociedades científicas de USA, destinado a los responsables de la política científica de aquel país, resumen las siguientes áreas de investigación para el desarrollo futuro de la teoría evolutiva: 1.- seguir documentando la historia de la diversidad; 2.- Tasas de extinción, el fenómeno de la extinción en masa y recuperación de ecosistemas (con clara repercusión en la gestión de la biodiversidad actual) y 3.- evolución de la forma orgánica y su significado en la existencia de los organismos, aspecto que trataremos en mayor detalle.

\section{Causas de la Evolución}

Durante décadas, la biología evolutiva y la paleobiología han estado dominadas por el paradigma neo-darvinista (también llamado adaptacionista). Dicho paradigma, lejos de haberse agotado, sigue vigente y se desarrolla en ámbitos como la genética de poblaciones, la ecología evolutiva, evolución del comportamiento, etc.

Darwin propuso a la selección natural -la supervivencia del más apto- como el agente fundamental del proceso de adaptación. Es decir, la facultad de los organismos para desarrollar las «herramientas biológicas» que les permiten reproducirse y explotar los recursos del medio con la mayor eficacia. Durante los años 40 y 50 del siglo XX, un conjunto de avances científicos dio lugar a la Teoría Sintética o Neo-darvinismo. En esencia, la incorporación de la mutación al azar actuando sobre los genes, entendidos como las unidades elementales de información que se trans- 
mite entre generaciones, proporcionó un soporte genético sólido a la teoría de la evolución por selección natural. Además, la acción de la selección natural modulando las frecuencias génicas en el seno de las poblaciones, acorde con criterios de eficacia reproductora, encontraba en el modelo gradual de cambio una base explicativa congruente: natura non facit saltum. Los paleontólogos, por su parte, tradicionalmente han estado en desacuerdo con este principio. En contradicción con el casi universal postulado del cambio gradual sostenido por el darvinismo, el registro fósil muestra discontinuidades en las transiciones morfológicas, revoluciones en las biotas del pasado, además de pautas de cambio sostenidas durante millones de años -las llamadas tendencias evolutivas-, y en otras ocasiones largos períodos de estasis morfológico en las especies. En definitiva, toda una fenomenología del mundo vivo que escapa a la visión unitaria de gradualismo sobre la que se apoya la teoría darviniana de la evolución. Es aquí donde se abrió un abismo entre neontólogos y paleontólogos. Los primeros, equipados con la observación de lo que está vivo y con las poderosas armas de la experimentación, han tendido a comprender la evolución como una extensión en el tiempo geológico de los procesos observables en la actualidad. Los segundos, acostumbrados a manejar la inmensidad del tiempo geológico, tienen ante sus ojos fenómenos de difícil explicación con un simple ejercicio de actualismo. Con la aceptación general de la Teoría Sintética, esta dialéctica desembocó en una incomprensión por parte de la Neobiología hacia la Paleobiología, que terminó relegando a ésta a un papel de mero ilustrador de los principios teóricos que emanaban de disciplinas como la genética de poblaciones.

Pero las cosas han cambiado. Desde los años 80, diferentes autores han proclamado con solvencia realidades ignoradas por la Teoría Sintética. El nuevo resurgir de la Paleontología evolutiva ha proclamado la existencia de procesos macroevolutivos; es decir, aquellos que suceden por encima del nivel de especie y que han dado lugar a la diversidad y disparidad de las múltiples organizaciones biológicas ¿Cómo interpreta la teoría sintética los procesos macroevolutivos? La idea es simple: los procesos evolutivos pueden interpretarse como la extensión en largos periodos de tiempo de las leyes que rigen los fenómenos microevolutivos (las dinámicas que ocurren en el seno de las poblaciones). Es la adición de ese ingente tiempo geológico lo que posibilita los grandes cambios. Ante este planteamiento, en los últimos años algunos paleobiólogos se han planteado la pregunta: ¿pueden extrapolarse sin más los procesos que suceden en unos cuantos años a los procesos evolutivos inscritos en un tiempo geológico? La respuesta es no. Existen fenómenos que no son 
explicables con la extensión en el tiempo de las leyes microevolutivas.

Creo que no se exagera si afirmamos que Stephen J. Gould es el autor más influyente en la paleobiología de los últimos 30 años. En un artículo de gran influencia Gould (1995) analiza los pilares del darwinismo y los posibles fundamentos de una teoría de la macroevolución. En su opinión las críticas al neo-darvinismo se pueden articular en torno a los tres puntos siguientes (Figura 1).

\section{Debates actuales en Paleobiología}

\section{Neo-darwinismo \\ Teoría Macroevolutiva}

\section{1.- Creatividad de la selección natural}

Morfoespacio contínuo

Variación al azar

\section{2.- Niveles de selección}

A nivel de organismo

\section{3.- Eficacia de la selección natural \\ 3. Eficacia de la seleccion natural}

\section{Extensión de procesos} microevolutivos

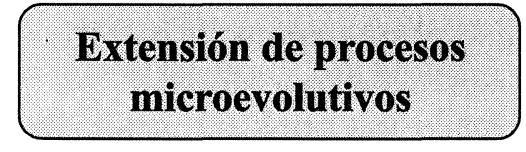

\section{Morfoespacio discontínuo}

Restricciones del desarrollo
Jerarquía de niveles.

Selección de especies

Direccionalidad, Catástrofes

Figura 1. Resumen de la discusión actual sobre teoría evolutiva, en sus vertientes micro y macroevolutiva, basada en la discusión de los tres principios básicos de la Teoría Sintética discutidos por Gould (1995).

1. La creatividad de la selección natural. La selección natural es un agente primordial en evolución. No obstante su papel es eliminatorio. El organismo propone (variación al azar) y el ambiente dispone. ¿Pueden las nuevas formas surgir a través de otros procesos? Los críticos del darvinismo opinan que deben existir otros procesos que expliquen las novedades evolutivas al margen del potencial creativo de la selección natural. Entre las propuestas figuran los procesos de heterocronía y las restricciones del desarrollo. Las trataremos después. 


\section{Programas de Investigación en Paleobiología y Teoría evolutiva}

2. Niveles a los que actúa la selección natural. El darvinismo sostiene que la selección natural actúa a nivel de los organismos en función de su éxito reproductivo individual. Con la proposición del modelo del equilibrio puntuado (Eldredge \& Gould, 1972; Gould \& Eldredge) se ha planteado la teoría jerárquica de la selección. Es decir, la selección natural puede actuar a diferentes niveles desde el puramente genético al nivel de especies o clados (Vrba and Eldredge, 1984). El modelo de la selección de especies, basado en un principio de éxito diferencial en la supervivencia de las especies, es quizá el que más desarrollo ha tenido dentro la paleobiología.

3. Eficacia de la selección natural en extensión. El neo-darvinismo sostiene que de las dinámicas de población observadas durante unos pocos años (cambios en frecuenias alélicas), extendidas en el tiempo geológico puede explicar el proceso evoltutivo. Sin embargo, no está nada claro que dicho mecanismo pueda dar cuenta del cambio genealógico en todos los niveles taxonómicos. Gould (1995) señala dos clases de fenómenos que no concuerdan con el principio de extensión. Por un lado, los eventos de gran magnitud que ocurren de forma infrecuente tales como el impacto de meteoritos y su influencia sobre la biodiversidad, la coalescencia de placas continentales, cambios climáticos. $Y$ por otro, procesos que operan a niveles superiores o a tasas mucho más lentas de las que puedan ser detectadas en lo inmediato de la actualidad. Es en este marco donde adquieren su máximo sentido el análisis de la evolución de la diversidad, las tasas de extinción en diferentes linajes y momentos, y recuperación de los ecosistemas y de los diferentes grupos taxonómicos tras una situación de crisis (Kirchner and Weil, 2000; Erwin, 2000) (Figura 2).

A juzgar por los trabajos publicados en los últimos años, de los puntos previamente señalados los que más desarrollo intelectual y empírico están alcanzando son los que conciernen a la discusión sobre el papel creativo de la selección natural y la eficacia de la selección natural en extensión. El modelo de selección de especies, por el contrario, parece que no ha propiciado tanta aceptación.

\section{Evolución de la forma}

El estudio de la forma orgánica, su variación y su evolución es un tema clásico de las ciencias naturales que tuvo su mayor explendor en el desarrollo de la Anatomía Comparada. El estudio de la forma siempre ha estado organizado en torno a la dialéctica estructura/función ¿Qué determina la diversidad de los seres vivos? ¿La realización de funciones en un contexto ecológico? ¿o existen leyes que gobiernan la estructura al mar- 


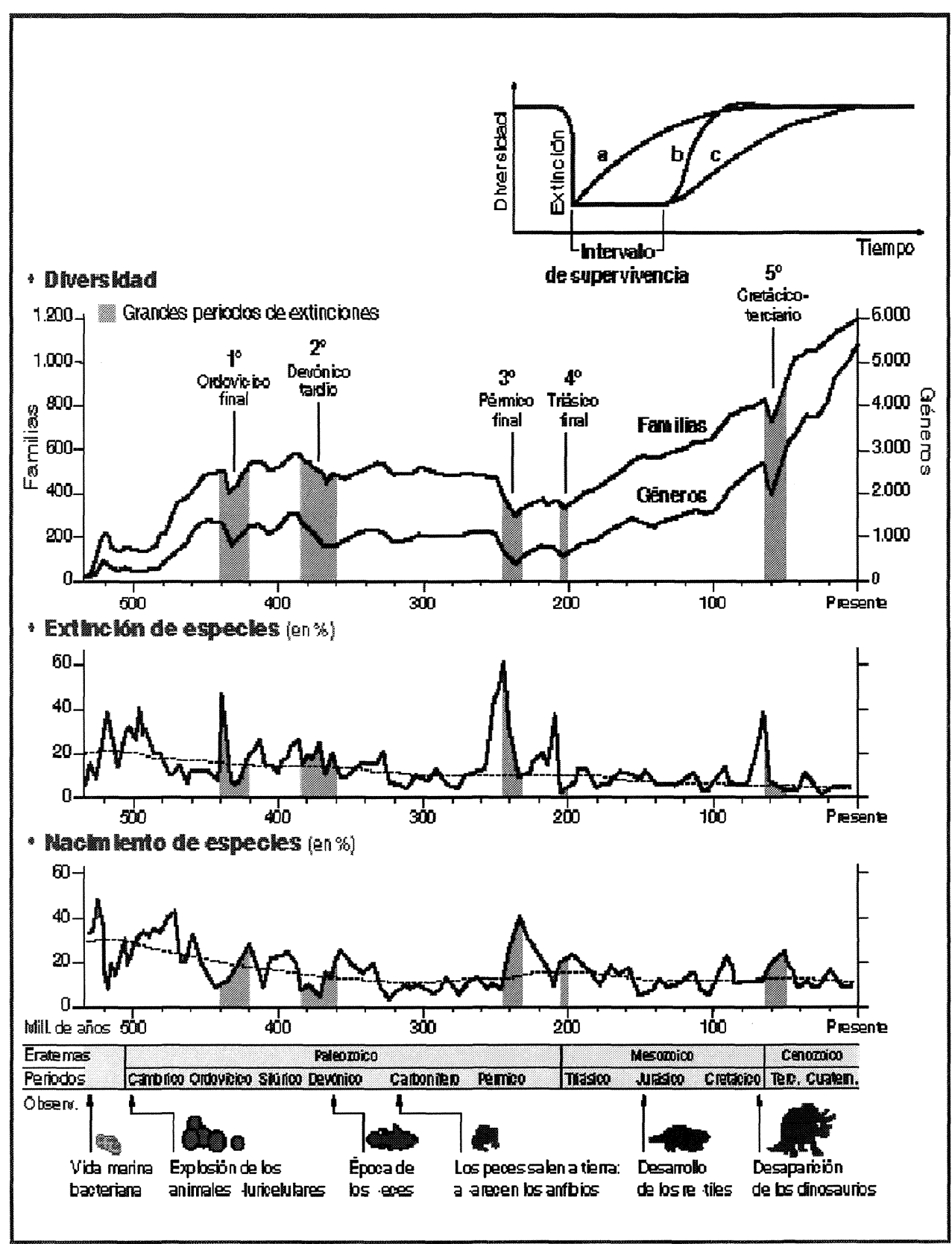

FIgURA 2. Análisis de la evolución de la diversidad, grandes extinciones y pautas de recuperación de taxones según Kirchner and Weil (2000) (imagen adaptada del diario El País). 
gen de las funciones que realizen? Con la aceptación general de la Teoría Sintética, el debate sobre «estructura y función» quedó casi enmascarado por el éxito de la biología funcional. La paleobiología, en este sentido, ha jugado un papel muy importante al seguir planteando desde el estudio del registro fósil cuestiones de esta naturaleza. En la actualidad, la reciente incorporación de datos y conceptos nuevos esta reactivando el problema de la forma, adquiriendo nuevos enfoques. Paradójicamente, el retorno a viejas preguntas viene de la mano de una biología funcional que necesita de la biología comparada y de la paleobiología para poder resolver sus propias cuestiones (Raff, 1996). El progreso en el conocimiento de las leyes de la herencia, apoyada en la biología molecular, ha devenido en una Genética del Desarrollo que converge en sus preguntas con el núcleo mismo de los problemas clásicos de la Anatomía Comparada y la Paleontología (ver Shubin et al., 1997; Carroll, 2000).

En la actualidad dos acontecimientos han reactivado el estudio de la morfología. De una parte, la irrupción en escena de la genética y biología del desarrollo con el descubrimiento de los genes reguladores del desarrollo. De otra, la discusión de la validez de las hipótesis filogenéticas construidas con datos moleculares frente a las derivadas de datos morfológicos.

El descubrimiento de los genes Hox y su conservación en amplios grupos de organismos nos está permitiendo comprender cómo se establece la información posicional que permite a las células saber su localización en el embrión y por ello como deben diferenciarse. La genética del desarrollo ha revelado un patrón de control genético en la evolución de los caracteres estructurales en metazoos bien distinto del preconizado por la genética mendeliana y de poblaciones. La evolución a gran escala -macroevolución- no es el resultado de selección de alelos alternativos o la acumulación de mutaciones, como preconiza la genética cuantitativa. Más bien parece que los grandes cambios estructurales derivan de la reutilización de un conjunto de redes de genes reguladores genéticamente homólogos. A la luz de estos datos no se puede pretender que la selección natural modele todas las direcciones evolutivas (Gould, 1995). Se pone de manifiesto la necesidad de un diálogo entre los factores externos que llevan a una adaptación y la existencia de limitaciones internas inherentes a la propia organización de los seres vivos. Poco a poco la ciencia va desvelando como los caminos evolutivos potenciales no son ilimitados ya que la propia organización de los sistemas orgánicos impone restricciones sobre el dominio de lo que es posible. He aquí un argumento claramente fuera del darvinismo que puede dar cuenta de fenómenos evolutivos a gran escala como, por ejemplo, las tendencias evolutivas. ¿Cuáles son las causas de esas limitaciones a los procesos evolutivos internas a los organismos? 


\section{Relaciones entre evolución y desarrollo individual}

El esclarecimiento de estas cuestiones parece estar íntimamente ligado al estudio de las relaciones ontogenia-filogenia. Es éste un campo de estudios con profundas raíces históricas que surge de la observación de cómo los caracteres de la forma adulta de las especies aparecen en estados embrionarios de sus hipotéticos descendientes. Como resultado de este tipo de observaciones, se enunciaron las conocidas cuatro leyes de von Baer así como la ley biogenética de Haeckel. Más recientemente, desde la poderosa influencia de la obra de Gould (1977) Ontogeny and Phylogeny, los estudios de heterocronía tuvieron un momento de auge en los pasados años 80. En la actualidad, con la incorporación de la biología molecular y la genética del desarrollo, una nueva disciplina informalmente denominada evo-devo (Evolution and Development; Raff, 1997) ocupa la atención central en la investigación de la evolución de la forma y sus leyes.

Una vez constatada la necesidad de considerar factores internos limitantes en la variación disponible, la forma más inmediata de abordar el problema es considerar que la variación a lo largo de las trayectorias ontogenéticas previamente existentes constituye el canal más inmediato para determinar una dirección filética. De aquí que el concepto de heterocronía-modificación de los tiempos y las tasas de desarrollo- haya servido de guía para el estudio de las relaciones ontogenia-filogenia (ver McKinney, 1988; McKinney y McNamara, 1991).

Los estudios sobre heterocronía, muy enraizados en la noción de recapitulación, sin embargo, a considerar el propio proceso de desarrollo como una unidad (aunque el fundamento de los modelos de heterocronía recae en una disociación de los procesos de crecimiento, desarrollo y maduración sexual). En particular, la noción de recapitulación recogida en la ley biogenética, considera que la evolución se ocasiona mediante el mecanismo de adición terminal de nuevos caracteres (es decir, adición de estados al final del desarrollo). La noción e investigación de la heterocronía perdió interés en gran medida por la exagerada proliferación de términos y por su carácter esencialmente descriptivo. Así, la descripción de una transformación morfológica terminaba reduciéndose a un catalogo de términos sin que se pudiera abordar el estudio de su organización (ver Rosas, 1989).

El estudio de la organización del fenotipo y su potencial de variación, estrictamente al azar o restringido, se ha aglutinado en torno a la noción de «restricciones del desarrollo» (en inglés, developmental constraints). Se entiende por «constraint»: un sesgo en la producción de variación de 
fenotipos o una limitación en la variabilidad fenotípica causada por estructura, carácter, composición o dinámica del desarrollo (ver trabajos en Bonner, 1982; Smith et al., 1985). Esta noción esta basada en el concepto de canalización y en la metáfora de los paisajes epigenéticos, elaborada por Waddington, en la que el sistema en desarrollo, representado por la bola que se desliza por una ladera, puede descender por una serie de canales previamente determinados (figura 3). Inspirado en esta concepción, las restricciones del desarrollo emergen naturalmente de la dinámica de sistemas complejos, simplemente por dos condiciones: que el sistema implique un elevado número de componentes y que la naturaleza de las interacciones sean no-lineales.

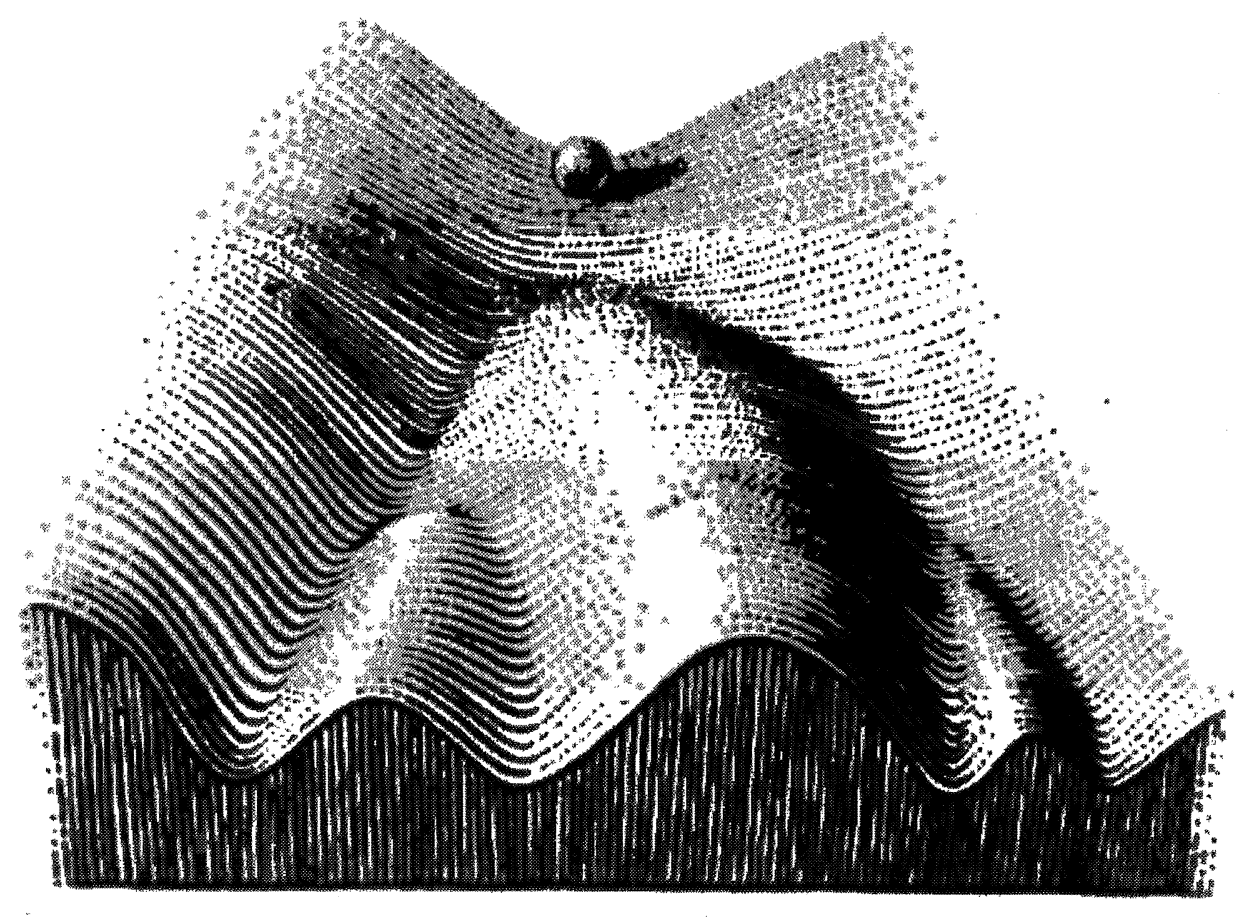

FiguRA 3. Representación gráfica de la metáfora de los paisajes epigenéticos propuesta por Waddington. La bola representa al fenotipo cuyo desarrollo puede tener lugar solo por canales determinados.

Alberch (1982) nos propone el siguiente planteamiento. Partiendo de una especie o taxón con un ámbito fenotípico determinado, se dan teóricamente dos posibilidades en su evolución: 1.- si la generación de formas es evolutivamente continua, aparecerá con el paso del tiempo un morfo- 
espacio mas o menos homogeneamente relleno. 2.- Si solo son posibles ciertas casos entonces el morfoespacio será rellenado de manera discontinua. En torno a este planteamiento se ha desarrollado una morfología teórica basada en la simulación de la forma orgánica mediante modelos matemáticos, para producir morfoespacios teóricos como una base para poder entender la lógica de la distribución de los fenotipos (figura 4). Alberch (1990) propuso que toda manifestación de orden en la naturaleza (desde los eventos de especiación a las tendencias evolutivas), puede deberse a dos posibles conjuntos de causas: por un lado, los procesos de adaptación, y, por otro, las propias limitaciones de la estructura. Qué peso tiene cada una de estas causas no es posible conocerlo a priori: es objeto de investigación (Sterns, 1992). Esta aportación teórica representa, además, un cambio epistemológico de primer orden ya que propone un programa de investigación donde se conjugan un amplio número de disciplinas al reunir las viejas preguntas de la Anatomía Comparada con los avances más recientes de la biología molecular. Incorpora, además, modelos de la teoría de sistemas dinámicos complejos y define un diálogo constructivo entre los paradigmas funcionalista y estructuralista de la evolución.

El neo-darvinismo sostiene que el proceso de adaptación es el primum movens del cambio evolutivo de la forma. La función es la causa primaria de la forma. La distribución de la diversidad se inscribe en el concepto de paisaje adaptativo, en el que cada fenotipo tiene adscrito un cierto valor de eficacia (fitness). Con el paso del tiempo, las dinámicas del medio ecológico y la selección natural van modulando las trayectorias evolutivas de las especies. La realización de este proceso exige un ejercicio de ensayo y error en el que los organismos produzcan una variación puramente aleatoria, a disposición de la selceción natural, que no esté limitada por su arquitectura genética o de desarrollo. Frente a la interpretación adaptativa de los caracteres cabe plantear la hipótesis de si la aparición de caracteres independientes en diferentes linajes puede significar que la evolución iterativa sea una consecuencia de restricciones actuando sobre la evolución morfológica por medio de la canalización del desarrollo. Eventos evolutivos diferentes que llevan a resultados morfológicos similares no siempre indican una explicación adaptativa común (Wake, 1991).

En el ámbito de la paleobiología, la noción de «restricciones del desarrollo» proporciona una base teórica para explicar las discontinuidades morfológicas observadas en el registro fósil. Éste constituye el mejor conjunto de datos para contrastar la influencia de un hipotética restricción. La literatura actual ofrece numerosos ejemplos de colaboración e inten- 


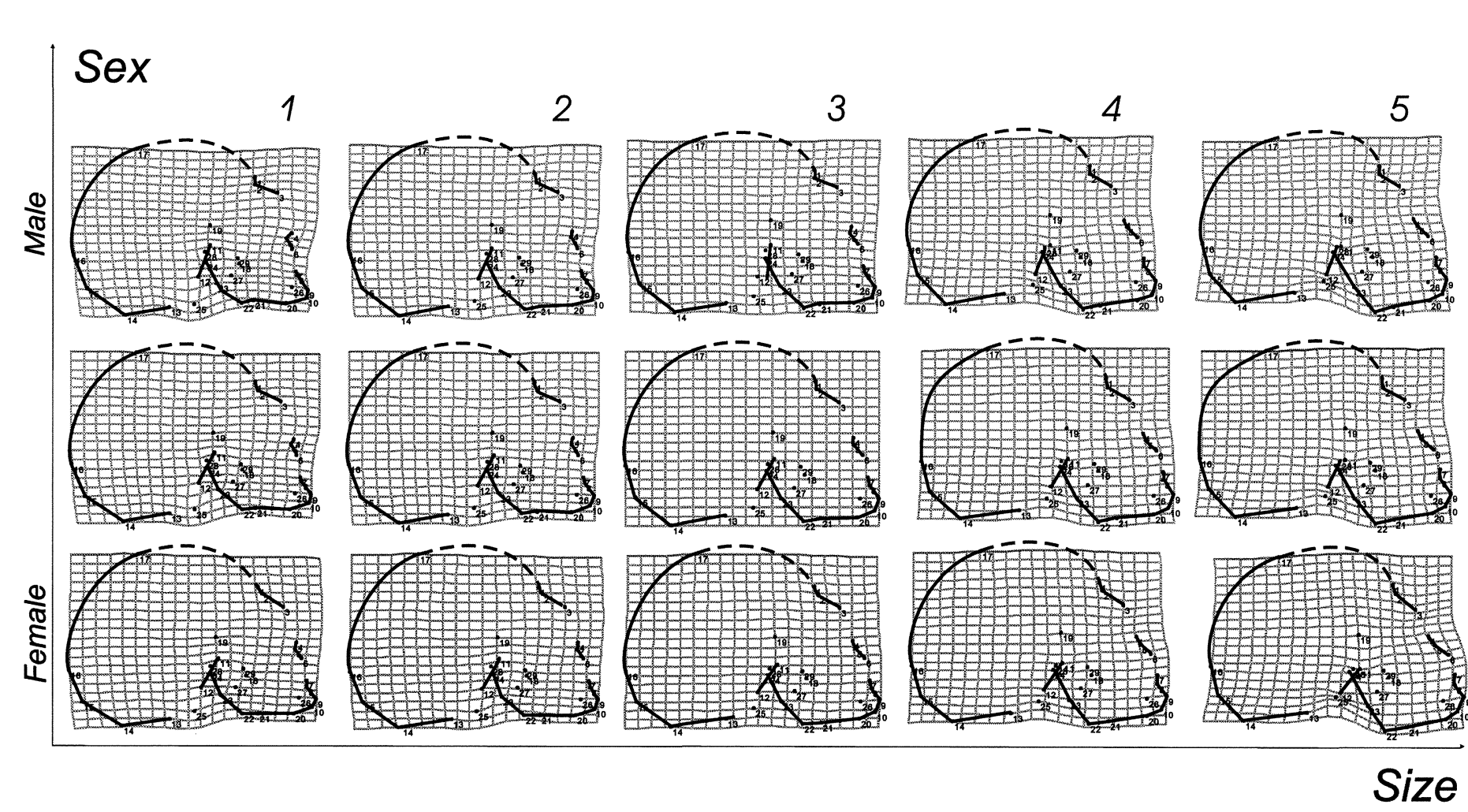

Figura 4. Morfoespacio en dos dimensiones de la interacción recíproca en la expresión morfológica en el complejo craneofacial de una población humana actual debida a dos factores: alometría y diferencias sexuales (según Rosas \& Bastir, 2002). 
tos de síntesis de los datos procedentes de la paleobiología y de la biología del desarrollo (Raff, 1997; Carroll, 2000; Carroll, 2001). La cooperación entre estos dos campos científicos se sustenta en la premisa de que paleontología nos dice lo que ha pasado realmente en la historia de la vida, mientras que la biología del desarrollo puede desvelar las pautas genéticas a través de las cuales han tenido lugar las transiciones observadas. El registro fósil muestra lo que realmente ha pasado. Esta constatación siempre será del todo necesaria.

\section{La necesidad de la filogenia y el efecto de la cladística}

La biología del desarrollo ha puesto nuevamente sobre el tapete la necesidad de distinguir entre caracteres homólogos y caracteres convergentes. Según comenta Raff (1997), los biólogos del desarrollo han tomado conciencia de la importancia de conocer la filogenia cuando se ha descubierto que genes que juegan papeles centrales en el desarrollo están muy extendidos entre los distintos phyla. Compartir genes reguladores del desarrollo implica un origen común -homología- para trayectorias de desarrollo muy diferentes. Esto plantea una paradoja: ¿cómo es posible que planes corporales tan dispares cómo los de un artrópodo y un vertebrado sean establecidos por los mismos genes reguladores del desarrollo? Para poder develar este tipo de cuestiones es imprescindible disponer de hipótesis filogeneticas robustas sobre las que discutir los diferentes aspectos de la homología.

Huelga decir que la cladística es la metodología más extendida para la reconstrucción de filogenias. Tradicionalmente las propuestas filogenéticas proceden del estudio de la morfología, y cuando los fósiles entran en los análisis, se emplean básicamente los caracteres del esqueleto. Desde la proposición de las llamadas filogenias moleculares han surgido numerosas de discrepancias en los resultados procedentes de uno y otro campo. Un buen número de autores reconoce en la actualidad la mayor consistencia de las filogenias moleculares. Sin embargo, hoy por hoy, no es factible la extracción de $\mathrm{ADN}$ de los fósiles por lo que el uso de la morfología sigue siendo obligado.

Sin embargo, la trascendencia de este debate no es tanto la discusión de si unos datos son mejores que otros, en cuyo caso se llegan a mezclar intereses de gremio. La paradoja reside en la discrepancia tan marcada entre los resultados moleculares y los morfológicos ¿por qué la evolución morfológica en ocasiones se aleja tanto de la pauta filogenética? En los análisis cladísticos la homoplasia (convergencia y evolución paralela) 
aparece con una frecuencia inusitada. Esta circunstancia está dando lugar a una reconsideración de cómo emplear los caracteres de forma en la reconstrucción filogenética. En este contexto surgen un aspecto importante y es que los análisis cladísticos exigen que los caracteres que entran en el análisis sean independientes. Sin embargo, las interacciones que ocurren en múltiples niveles jerárquicos del desarrollo -desde genes individuales a módulos estructurales- dificultan y confunden sobremanera los intentos de definir qué caracteres son realmente independientes. Se plantea aquí un importante problema teórico y metodológico en biología evolutiva. El organismo no es un sumatorio de rasgos sino un complejo sistema integrado. Esclarecer estos aspectos plantea la necesidad de considerar los caracteres morfológicos en términos de sus procesos generativos.Y en cierto sentido, con este planteamiento, se cierra el bucle entre morfología y biología del desarrollo.

Mucho nos queda por aprender en biología evolutiva. En este ensayo hemos dado una rápida visión del estado actual de algunos aspectos de esta fascinante disciplina. Una conclusión general parece emerger. La vida es un fenómeno extraordinariamente complejo con múltiples manifestaciones en sus distintos niveles de organización. El denominado problema de la forma está íntimamente asociado a dos de las grandes cuestiones de la biología. Uno es el denominado problema de la representación. Es decir, como una información codificada en secuencias de ADN encuentra su representación en un fenotipo tridimensional y sujeto a una fisiología. La morfología es el producto del desarrollo, el cual esta controlado por programas genéticos reguladores. Y, a escala evolutiva, el otro gran problema de la biología es la relación entre el desarrollo individual del organismo (ontogenia) y las pautas de evolución de su linaje (filogenia), o viceversa. Las diferentes disciplinas -unas clásicas, otras muy recientes- convergen en las mismas preguntas de fondo y solo mediante ensayos serios de integrar todos estos aspectos podremos avanzar en el conocimiento de la evolución orgánica.

\section{Agradecimientos}

Agradezco al Dr. Máximo Sandín el ofrecimiento de publicar este trabajo. A mis compañeros del Departamento de Paleobiología del Museo Nacional de Ciencias Naturales con los que he tenido ocasión de discutir algunos aspectos de los temas aquí recogidos, especialmente a Markus Bastir y Manolo Nieto. La investigación del autor se inscribe en el proyecto BXX2000-1258-CO3-01 del MCYT. 


\section{Bibliografía}

Alberch, P. (1982). Developmental constrains in Evolutionary Process. J.T. Bonner (Ed). Evolution and Development. Springer-Verlag, Berlin. 313-332.

ALBERCH, P. (1990). Natural selection and developmental constraints: external versus internal determinants of order in nature. En (C.J. DeRousseau, Ed). Primate life history and evolution. Wiley-Liss, Inc. New York 15-35 pp.

BonNer, J. (ed.) (1982). Evolution and Development. Berlin: Springer-Verlag

CARROLL, R. L. (2000). Towards a new evolutionary synthesis. TREE 15: 27-32.

CARROLL, S. B. (2001). Chance and necessity: the evolution of morphological complexity and diversity. Nature 409: 1102-1109.

ELDREDGE, N., \& GoULD, S. J. 1972. Punctuated equilibria: an alternative to phyletic gradualism. En (T. J. M. Schopf, Ed.) Models In Paleobiology.

ERwin, D. (2000). Life's downs and ups. Nature 404: 129-130.

FErguson, D. K. (1997). The State of European Paleontology. EuroPal 11/12: 10-12.

FERNÁNDEZ LÓPEZ, S. (1989). La materia fósil. Una concepción dinamista de los fósiles. En (E. Aguirre, ed.). Paleontología. Nuevas Tendencias. Madrid: CSIC, pp. 25-46.

Futuyma, D. J., Meagher, T. R., Donoghue, M. J., Langley, C. H. and MaXson, L. (1997). Evolution, Science and Society: a "white paper» on behalf of the field of evolutionary biology. (http://www.rci.rutgers.edu/-ecolevol/fulldoc.htm).

Gould, S. J. (1977). Ontogeny and Phylogeny. Harvard University Press.

Gould, S. J. (1995). A task for Paleobiology at the threshold of majority. Paleobiology 21: 1-14.

Gould, S. J., \& EldREDGe, N. (1977). Punctuated equilibria: the tempo and mode of evolution reconsidered. Paleobiology, 3, 115-151.

HuxLey, J. (1942) Evolution: The Modern Synthesis. George Allen and Unwin Lts. London. $\mathrm{Pp} 645$

JABLONSKI, D. (1999). The Future of the Fossil Record. Nature 284: 2114-2116.

Kirchner, J. W. and WeIL, A. (2000). Delayed biological recovery from extinctions throughout the fossil record. Nature 404: 177-180.

López-Martínez, N. \& Truyols Santonja J. (1994). Paleontología. Madrid: Síntesis, 334 pp.

McKinney, M. L. (1988). Heterochrony in Evolution. M.L., McKinney. Plenum Press, New York.

McKinney , M. L. \& McNamara, K. J. (1991). Heterochrony: The Evolution of Ontogeny. Plenum Press.

Shubin, N., TABIN, C. \& CARROLL, S. B. (1997). Fossils, genes and the evolution of animal limbs. Nature 388: 639-648.

Maynard Smith J, Burian R, Kauffman S, Alberch P., Campbell J., Goodwin B., Lande R, RAAP D., WOLPERT L., 1985. Developmental constraints and evolution. Q Rev Biol 60:265-287.

RAFF, R. A. (1994). The Shape of Life. Genes, development and the evolution of animal form. Chicago University Press, 520 pgs.

Rosas, A. (1989). Paleontología, Ontogenia y Heterocronía. En (E. Aguirre, ed.). Paleontología. Nuevas Tendencias. Madrid: CSIC, pp. 83-108.

Rosas, A. \& BASTIR, M. (2002). Thin-plate spline analysis of allometry and sexual dimorphism in the human craniofacial complex. Am. J. Phys. Anthropol. 117: 236-245

SteRns, S. C. (1992). The Evolution of Life Histories. Oxford University Press. 


\section{Programas de Investigación en Paleobiología y Teoría evolutiva}

VRBA, E. S and EldREDGe, N. (1984). Individuals, hierarchies and processes: towards a more complete evolutionary theory. Paleobiology 10: 146-171.

WAKE, D. B. (1991). Homoplasy: The Result of Natural Selection, or the Evidence of Design Limitations? American Naturalist 138: 543-567. 